\title{
A Possibilidade da Educação Jurídica numa Perspectiva Humanista
}

\author{
The Possibility of Legal Education with a Humanist Perspective
}

Sirlane Melo

Resumo: A sociedade atual revela tensões que apontam para uma crise de valores, de esperança, imersos na violência e com grande parte da população sem condições dignas de sobrevivência. No mundo jurídico atual, o das normas, não importa a realidade vivenciada, sentida e desejada pelos cidadãos. Recuperar o destinatário do Direito, é o que vêm procurando fazer as correntes humanistas do Direito. Repensar a educação jurídica e a aplicação da teoria do humanismo no seu contexto, a fim de verificar uma possibilidade para construção e efetivação da cidadania da população de baixa renda, é importante para que se possa não apenas formar bacharéis em direito, mas também e principalmente, operadores de direito conhecedores e comprometidos com a sociedade em que estão inseridos. É possível, através do ensino do direito, calcado num novo humanismo ocorrer mudanças concretas de forma a integrar-se no objetivo de construir uma realidade mais justa e digna.

Palavras-chave: Educação Jurídica. Humanismo. Acesso à Justiça e Cidadania.

\begin{abstract}
Today's society reveals tensions which signify a crisis of values and hope, immersed in violence and great part of the population has no decent conditions to survive. In the current legal world, the standard one, it does not matter the experienced, perceived and desired reality by citizens. Recovering the address of the law, it is what the humanist currents of law have been trying to do. Rethinking the legal education and how applying the humanism theory in its context, to check the possibility for building and activating citizenship of low income population, it is important not just to train law graduates, but also and especially, legal practitioners who are experts and committed to the society at all levels. It is possible, by the teaching of law, modelled on a new humanism to take place concrete changes in order to be integrated into the aim of making a fairer and more decent reality.
\end{abstract}

Keywords: Legal Education. Humanism. Access to Justice and Citizenship.

Artigo recebido em 28 abr. e aprovado em 2 maio 2016. 


\section{Introdução}

As tensões sociais contemporâneas revelam uma crise de valores e de perspectiva de futuro. A violência onipresente e o grande número de pessoas sem condições dignas de sobrevivência pedem que o sistema jurídico deixe de ser um meio que não se preocupa com o fim, que vá além do formalismo das normas, voltando-se para o homem e seus anseios. Assim, as correntes humanistas do Direito dedicam-se à valorização daquele a quem a ciência jurídica se destina, ou deveria se destinar: o ser humano.

Repensar o sistema jurídico passa necessariamente pelo âmbito da educação jurídica em todas as suas dimensões. As diferenças sociais e os ataques constantes à dignidade da pessoa humana relativizam o conceito e a prática da cidadania. Assim, o compromisso da educação jurídica não deve ser meramente com a exegese e a reprodução das normas, mas com a formação de bacharéis conscientes de que um novo humanismo pode interferir de modo efetivo na construção de uma realidade mais justa e digna. A educação jurídica implica, pois, no avanço do ensino jurídico de meramente informador para a educação jurídica que informa e forma.

Este artigo inicia-se com um breve resgate histórico do humanismo ocidental, a fim de reunir elementos de compreensão do momento atual. Após, faz-se algumas considerações sobre os conceitos de humanismo, cidadania e acesso à justiça, para concluir com um olhar sobre o potencial transformador do humanismo aplicado à educação jurídica, como forma de vincular os futuros operadores do Direito a uma prática jurídica garantidora dos direitos fundamentais.

\section{O Moderno Discurso da Cidadania}

Para obter consenso e coesão social, o Estado liberal utiliza-se de mediações conceituais, tais como nação, povo e a formatação do discurso da cidadania. Este quadro de construção histórica foi analisado por T.H. Marshall dentro de uma específica experiência nacional, a inglesa, e acabou por se tornar um modelo paradigmático e ponto de partida para todos aqueles que enfrentam a temática da cidadania. 
Segundo Marshall (1977) ${ }^{1}$, a cidadania seria composta dos direitos civis e políticos - direitos de primeira e segunda gerações, e dos direitos sociais, direitos de terceira geração. Os direitos civis, conquistados no século XVIII, correspondem aos direitos individuais de liberdade, igualdade, propriedade, de locomoção, à vida e à segurança. São os direitos que dão embasamento à concepção liberal clássica. Já os direitos políticos, alcançados no século XIX, dizem respeito à liberdade de associação e reunião, de organização política e sindical, à participação política e eleitoral, ao sufrágio universal etc.. "São também chamados direitos individuais exercidos coletivamente e acabaram incorporando-se à tradição liberal." 2

Segundo Santos, os direitos sociais foram consagrados no século XX como resultado das lutas contra as desigualdades econômicas ${ }^{3}$ :

Os direitos civis correspondem ao primeiro momento do desenvolvimento da cidadania, são os mais universais em termos da base social que atingem e apoiam-se nas instituições do direito moderno e do sistema judicial que o aplica. Os direitos políticos são mais tardios e de universalização mais difícil e traduzem-se institucionalmente nos parlamentos, nos sistemas eleitorais e nos sistemas políticos em geral. Por último, os direitos sociais só se desenvolvem no nosso século (XX) e, com plenitude, só depois da Segunda Guerra Mundial; têm como referências sociais as classes trabalhadores e são aplicados através de múltiplas instituições que, no conjunto, constituem o Estado Providência. (SANTOS, 1996, p. 120).

Embora didática, é importante ressaltar que a classificação geracional dos direitos, transposta para a realidade dos países periféricos, serviu para justificar e camuflar intenções políticas autoritárias. Como aponta Trindade ${ }^{4}$, "quantos governos, a pretexto de buscarem a reali-

${ }^{1}$ MARSHALL, T. H. Cidadania, classe social e status. Tradução de Meton Porto Gadelha. Rio de Janeiro: Forense, 1977, p. 56-109.

2 ANDRADE, Vera Regina P. de. Cidadania: do direito aos direitos humanos. São Paulo: Acadêmica, 1993, p. 124.

${ }^{3}$ SANTOS, Boaventura de Souza. Pela mão de Alice: o social e o político na pós-modernidade. São Paulo: Cortez, 1996. p. 120.

${ }^{4}$ TRINDADE, Antônio Augusto Cançado. América latina hoje. Entrevista com o autor. Proposta. p.48. 
zação progressiva de certos direitos econômicos e sociais em um futuro indeterminado, violaram sistematicamente os direitos civis e políticos.". Por outro lado, continua 5, "quantos governos têm buscado se escudar nas conquistas dos direitos civis e políticos para negar a vigência dos direitos econômicos, sociais e culturais.". E conclui o autor, "para que os direitos continuem a expandir-se e a fortalecer-se impõe-se uma visão necessariamente integral dos direitos humanos a abarcar todos os domínios da atividade humana (o civil, o político, o econômico, o social e o cultural).". 6

Percebe-se, pois, a crise da concepção liberal da cidadania, que na teoria constitucional moderna via o cidadão como o indivíduo que tinha vínculo jurídico com o Estado (nacionalidade) e era portador de direitos e deveres fixados por uma constituição (legitimidade). Os cidadãos, nesta concepção, são livres e iguais perante à lei, mas opera-se, segundo Andrade ${ }^{7}$, uma separação entre o homem e o cidadão que tem:

como pressuposto, outra dicotomia estrutural do liberalismo que é a separação Estado/sociedade civil (arcabouço institucional e discursivo do Estado de Direito capitalista), segundo o qual o Estado é identificado com o espaço público, ou seja, com o lugar do poder e da política e a sociedade civil identificada com o espaço privado da vida, a saber, com o lugar da economia ou das relações econômicas (mercado) e domésticas. (ANDRADE, 1988, p. 123-134).

Este conceito de cidadania tem sido rediscutido a partir da necessidade de transpor a concepção meramente formal associada à democracia representativa (votar e ser votado) para uma concepção que incorpora as necessidades humanas fundamentais, ou seja, uma perspectiva material da cidadania e uma democracia participativa. Cidadania não é apenas uma relação entre o Estado/sujeito, mas sim uma relação entre sujeito/sujeito, possibilitada e facilitada pelo Estado.

Por outro lado, há o surgimento da cidadania associada ao terceiro setor e à sociedade civil, na qual a participação "tende a ser mais

${ }^{5}$ Idem., ibidem, p.48

${ }^{6}$ Idem, ibidem, p. 48

7 ANDRADE, Vera Regina P. Cidadania, direitos humanos e democracia: reconstruindo o conceito liberal de cidadania. In: Reinaldo Pereira e Silva.(Org.) Direitos humanos como educação para a justiça. São Paulo, 1988, p.123-134. 
social e construída sobre redefinidas solidariedades e sobre temas mais pontuais." 8 (DELGADO, 1998, p. 144). Isto identifica-se "com a mobilização social unificada do processo que se fazia desde uma perspectiva política estatista homogeneizadora e centralizada, senão que pode ser adequada para amplos setores, como consciência de novos direitos para uns e de protestos contra exclusão para outros." ${ }^{9}$. Percebe-se, "uma orientação pelo controle e pela distribuição, para uma participação cidadã em movimentos temáticos e temas de qualidade de vida." ${ }^{10}$.

É dentro dessa perspectiva que se resgata o conceito de dignidade humana e a proteção dos direitos fundamentais consagrados na Constituição brasileira, para estabelecer-se uma relação entre o Direito e a Justiça, tendo como eixo o humanismo e a busca do acesso à justiça como um dos direitos primordiais para a realização de uma cidadania plena.

Compreende-se, assim, a preocupação com a construção democrática vista como um processo incessante dos sujeitos do Direito e da cidadania. Neste contexto, coloca-se a Justiça Social como parâmetro fundamental de aferição da legitimidade de um Estado de Direito.

\section{Acesso à Justiça}

A questão do acesso à justiça, a partir da Constituição Brasileira de 1988, tem sido alvo de várias críticas por parte de operadores do direito e de estudiosos que buscam minorar os obstáculos formais e operacionais aos grupos sociais mais vulneráveis, e que buscam a materialidade de seus direitos fundamentais.

Entre esses estudos, merece destaque a obra Acesso à Justiça de Cappelletti e Garth ${ }^{11}$ (1988). Os autores localizaram as tendências históricas sobre os diversos enfoques acerca do tema sobre o acesso à Justiça, percebendo um processo de mudança a respeito do conceito de acesso à Justiça, migrando de uma visão mais formalista e individualista (tipica-

${ }^{8}$ DELGADO, Daniel Garcia. Estado nación y globalización. Buenos Aires:Ariel, 1998, p. 144.

9 Idem. Ibidem, p. 145

${ }^{10}$ Idem. Ibidem.,p.146

${ }^{11}$ CAPPELLETTI, Mauro; GARTH, Bryant. Acesso à justiça. Tradução de Ellen Gracie Nothfleet. Porto Alegre: Antônio Fabris Editor, 1988, p.12. 
mente do século XVIII) para uma noção de efetividade e de importância social do direito ao acesso à Justiça.

$\mathrm{O}$ destaque principal dado à evolução do conceito de acesso à Justiça está no fato de que aquele, antes meramente formal e voltado para direitos individuais, em momento específico, passou a ser ressignificado em sentido substancial, passando a ser considerado como o mais básico dos direitos humanos.

A evolução econômica da sociedade ocidental, depois da Revolução Industrial, cuja estrutura está centrada no capitalismo, gerou uma série de situações de desigualdades (com destaque aos seus aspectos trabalhistas). As relações sociais ficaram expostas a desequilíbrios, principalmente no que tange à relação trabalho-capital. Neste sentido, maior grau de acesso à justiça pode ser considerado como um dos mais significativos instrumentos de resistência às injustiças social, econômica e política.

Conforme Carneiro ${ }^{12}$,

Estamos no Estado social, o estado intervém visando a assegurar não mais aquela igualdade puramente formal, utópica, concebida pelo liberalismo, mas a procura de uma igualdade material, permitindo que os mais desfavorecidos tivessem acesso à escola, à cultura, à saúde, à participação, àquilo que já se sustentava no passado, a felicidade. (CARNEIRO, 1999, p. 21).

Para que isso se efetive, Carneiro (1999) ${ }^{13}$ enfatiza que o "importante é que os direitos que promanam da liberdade e da igualdade, como a cidadania, a saúde, a educação, a informação, possam, na prática, ser alcançados, e exigidos de quem está obrigado a fornecê-los.”.

Dessa forma, ao Poder Judiciário compete a responsabilidade de proteger, efetivamente, os direitos individuais e coletivos. Entende-se que o caminho proposto pelo acesso à justiça necessariamente desemboca em formas efetivas de justiça para a população em geral, mas visando, basilarmente, contribuir para o impedimento das desigualdades sociais.

${ }^{12}$ CARNEIRO, Paulo Cezar Pinheiro. Acesso à justiça. Rio de Janeiro: Forense, 1999, p.21.

13 Idem, Ibidem, p.25 
Para compreensão do significado do acesso à justiça, buscam-se os ensinamentos de alguns que o conceituam, como Sanches (1987) ${ }^{14}$ que afirma: "toda e qualquer pessoa, física ou jurídica, deve ter acesso à Justiça, ou seja, a possibilidade de obter prestação jurisdicional do Estado, imparcial, rápida, eficaz, eficiente e barata.”. O autor enfatiza que o acesso deve proporcionar, com a maior rapidez e imparcialidade possível, a solução do conflito de forma eficiente e a baixo custo, caso contrário o acesso à justiça torna-se praticamente inatingível e problemático.

Rodrigues ${ }^{15}$ enfatiza com propriedade o tema, ao afirmar que

Se de um lado não se pode reduzir a questão do acesso à justiça à criação de instrumentos processuais adequados à plena efetivação dos direitos, de outro, é também evidente que não se pode afastar a ideia de acesso à justiça do acesso ao Judiciário. Os outros direitos, em última instância, dependem desse acesso sempre que não forem respeitados; sem ele a cidadania se vê castrada, impotente. Há aqueles conflitos que podem e devem ser solucionados através de instrumentos paraestatais ou privados. Mas é fundamental perceber-se que o Estado, sem a jurisdição, seria uma instituição política desprovida de um instrumento legítimo, através do qual possa exercitar seu poder, em última instância, na busca da pacificação da sociedade. Sempre que um direito não for respeitado espontaneamente, não há como fazê-lo legitimamente senão através do processo. (RODRIGUES, 1994, p. 29).

$\mathrm{O}$ ponto crucial do acesso à justiça é exatamente viabilizar à população que o busca, não somente a solução do conflito, mas também o esclarecimento de seus direitos, como cidadãos. Watanabe (1988) ${ }^{16}$ afirma que a "problemática do acesso à Justiça não pode ser estudada nos acanhados limites do acesso aos órgãos judiciais já existentes. Não se trata apenas de possibilitar o acesso à Justiça enquanto instituição estatal, e sim de viabilizar o acesso à ordem jurídica justa.”.

14 SANCHES, Sydney. Acesso à justiça. Revista dos Tribunais, São Paulo, v. 621, jul. 1987 , p. 266

15 RODRIGUES, Horácio Wanderlei. Acesso à justiça no direito processual brasileiro. São Paulo: Acadêmica, 1994, p. 29.

16 WATANABE, Kazuo. Acesso à justiça e sociedade moderna. GRINOVER, Ada Pellegrini, DINAMARCO, Cândido Rangel, WATANABE, Kazuo (coords.). Participação e Processo. São Paulo: Revista dos Tribunais, 1988, p. 128. 
Para Cappelletti (1988) 17 “o acesso à justiça pode, portanto, ser encarado como o requisito fundamental - o mais básico dos direitos humanos - de um sistema jurídico moderno e igualitário que pretenda garantir, e não apenas proclamar os direitos de todos.”.

E é a partir disso e da constatação de como se organiza e constrói a sociedade, que se fala em "assistência jurídica integral e gratuita". Há que refletir, porém, sobre o tipo de acesso à justiça que as pessoas estão tendo, especialmente as excluídas, muitas vezes semianalfabetas, que acorrem ao Judiciário.

No que se refere à assistência judiciária, é possível retomar os ensinamentos de Watanabe (1987) ${ }^{18}$ quando coloca que a expressão "assistência judiciária" pode ser entendida em várias acepções, explicando duas delas: uma no sentido restrito e outra no sentido amplo.

$\mathrm{Na}$ acepção restrita significa assistência técnica prestada por profissional legalmente habilitado, que é o advogado em juízo. Quando muito, assistência prestada na fase pré processual, mas sempre com vistas a uma demanda e à pessoa com conflito de interesse determinado. Na acepção ampla tem o sentido de assistência jurídica em juízo e fora dele, com ou sem conflito específico, abrangendo, inclusive, serviço de informação e de orientação, e até mesmo de estudo crítico, por especialistas de várias áreas do saber humano, do ordenamento jurídico existente, buscando soluções para sua aplicação mais justa e, eventualmente, sua modificação e, inclusive, revogação. Mais adequado seria chamar-se serviço de semelhante amplitude de "assistência jurídica", ao invés de "assistência judiciária”. (WATANABE, 1987, p. 250).

Nesse sentido, por ser essa uma questão inquietante e por ter claro que a assistência jurídica aos carentes envolve mais do que o acionamento do poder judiciário, mas também assessoria preventiva e extrajudicial, é que se pretende estudar a aplicação da teoria humanista latina na educação jurídica, como forma de conscientizar os futuros operadores do direito para atuarem de modo a contemplar e preservar a garantia

${ }^{17}$ CAPPELLETTI, Mauro, GARTH, Bryant. Acesso à justiça. Tradução de Ellen Gracie Nothfleet. Porto Alegre. Antonio Fabris Editor, 1988, p. 12.

18 WATANABE, Kazuo. Assistência judiciária e o juizado especial de pequenas causas. Revista dos Tribunais. São Paulo, v. 617, mar. 1987, p. 250.

Resenha Eleitoral (Florianópolis), v. 20, n. 1, p. 201-220, jul. 2016 
constitucional do acesso à justiça para todos, auxiliando na edificação da cidadania da população de baixa renda.

Buscar o resgate, ou implantar mecanismos no sentido de fazer valer os direitos do cidadão, com o efetivo acesso à justiça, envolve não só os cursos de Direito. É tarefa que ultrapassa a academia e atinge toda a sociedade, pois é evidente que há um descompasso entre o ideal e o real no ensino do Direito e o que se espera dele.

A partir da concepção ampla de acesso à justiça, os cursos de Direito deixam de ter apenas a função de formar profissionais habilitados para representar seus clientes no foro em geral, e precisam contribuir de maneira significativa para a construção de uma ordem jurídica e social mais justa e focada na dignidade da pessoa humana, comprometidos, portanto, com a díade informação e formação.

Os profissionais do futuro deverão estar aptos a lidar com as necessidades da população. Antigas práticas pedagógicas necessitam ser revistas. A atuação do docente precisa de novos enfoques, redefinindo o ensino superior de modo geral e a educação jurídica em particular. $\mathrm{O}$ ensino é o reflexo do profissional de amanhã.

Considerando, ainda, que o curso de Direito tem deveres éticos para com a sociedade, cabe aos operadores do Direito atuar eticamente, além de proporem alternativas para reflexão sobre o curso e a sua verdadeira função na sociedade.

A relação existente entre a universidade e a sociedade não pode ser abstrata. $\mathrm{O}$ que se constata, quando há referência à educação do Direito, é que esta relação está se concretizando nos estágios e naquilo que eles proporcionam à comunidade. Porém, esta atuação na sociedade deve ser mais ampla e contínua; para isso é possível afirmar que a educação humanista no curso de Direito deve ser enfatizada e orientada por professores e demais funcionários que lá desenvolvem suas atividades, pois acredita-se que devam estar preocupados com o ser humano em sua integralidade.

É necessário (re)analisar o paradigma do ensino jurídico, seu formalismo e tecnicismo. Depara-se, neste início de século XXI, com uma nova sociedade que clama por um novo direito. Assim, por entender ser função também da universidade a transformação da sociedade, há necessidade de formar profissionais que compreendam e que lutem pelo exercício da cidadania, fazendo com que a Justiça efetivamente se materialize. 


\section{Humanismo e Educação Jurídica}

Uma reflexão sobre o humanismo importa necessariamente em breve resumo histórico de sua trajetória. Os alicerces do humanismo estão impregnados pela filosofia pré-socrática, assim conhecida porque antecedeu aos filosófos gregos Socrátes e seus discípulos, Platão e Aristóteles. Esse período pode ser melhor denominado conhecimento mítico, primitivo ou vulgar. "Filosófo" era classificado como aquele que persegue o conhecer, o saber. O homem estava envolvido com forças misteriosas, nas quais as divindades dominam a vida do homem, não conseguindo determinar-se com segurança. ${ }^{19}$

Num segundo momento, tem-se a Filosofia Ática, sendo a Grécia o centro de seu desenvolvimento. Nesse momento temos Sócrates, Platão e Aristóteles como figuras a sustentar o ápice na evolução da filosofia. Já tendo o problema humano como foco, tem-se ainda a natureza, a moralidade, o Estado, o espírito e a alma. As divindades, neste momento histórico, eram absolutas. O que leva ao próximo período chamado de "cosmológico", onde a natureza física e o universo eram o centro do interesse. A ideia do homem não era ainda o ponto central, mas a realidade cósmica em seus princípios.

No século V, inicia-se nova fase da filosofia na Grécia. Caracteriza-se este momento pela volta do homem sobre si mesmo, sobre sua vida e a finitude dela. Enfatiza Oliveira (2006) ${ }^{20}$, "o homem se dá conta de que tem que fazer questão de quem ele é.”. Há nesse caminhar histórico uma mudança de preocupações dos pensadores da época, passando do naturalismo dos pré-socráticos ao humanismo, ao qual se dedicaram os sofistas. ${ }^{21}$

A sofistíca, de cuja doutrina se originou os sofistas, é conforme Vilela (1965) 22, "o conjunto de doutrinas, métodos e atitudes intelectuais daqueles pensadores gregos da época socrática.”. Os sofistas provocaram discussões e reflexões sobre o homem - o homem no mundo e o homem

19 Sobre este período pré-socrático, ver OLIVEIRA, Odete Maria. Conceito de homem: mais humanista, mais transpessoal. Ijuí:Unijuí, 2006, p. 39 -42.

20 Op.cit., p. 54

21 Sofistas eram sábios e não filósofos que vendiam sua cultura como instrumento de formação do homem. Ver mais em OLIVEIRA, Odete Maria, op. Cit., p. 54-55.

${ }^{22}$ VILELA, Orlando. Iniciação filosófica. $2^{\mathrm{a}}$ ed. São Paulo: Dominus editora, 1965, p. 29 
pelo homem, as doutrinas sociais, o direito, a oratória, a literatura - de forma realista, sem idealismos, que afetaram significativamente a filosofia grega.

O sofista Pitagóras afirmou que "o homem é a medida de todas as coisas" ${ }^{23}$, sendo esta afirmação considerada um marco dos problemas humanos tão discutidos pelos sofistas. Resume Tobeñas (1962) ${ }^{24} \mathrm{o}$ pensamento dos sofistas de que "o homem é o protagonista, considerado como centro do mundo, não mais como parte de um todo natural que lhe sobrepõe e domina".

Em seguida tem-se o período histórico, no qual surge a religião, o cristianismo. Ressalta Oliveira (2006) ${ }^{25}$ que "diante das doutrinas filosóficas já abordadas, apresenta uma visão singular do homem, do mundo e dos humanismos", tendo como característica própria seu espírito de especial valorização do homem em todos níveis e com proteção aos marginalizados da sociedade, ou seja, os pobres, prostitutas e pescadores. Até então, alude Nogare (1994) ${ }^{26}$ "essas pessoas não valiam nada.[...] Essas criaturas passaram a ser tratadas como pessoas, [...] em virtude do reconhecimento explicíto de que todos são homens iguais diante de Deus e, portanto, têm os mesmos direitos fundamentais.".

Assim, poder-se-ia afirmar que o humanismo adquire consistência com a concepção cristã de que o homem é um ser superior no mundo. Com o renascimento, o humanismo adquire novas formas, não sendo completamente exato afirmar, conforme Tobeñas (1962) ${ }^{27}$, "ser o humanismo um produto do renascimento e que este trouxe consigo o descobrimento do homem individual. [...] Foi Santo Agostinho o verdadeiro descobridor da personalidade humana e o forjador do humanismo filosófico em sua espécie teocêntrica.”.

Nesta visão rápida da trajetória histórica do humanismo, adentra-se, então, no humanismo moderno, tendo como característica o antropocêntrico, ou seja, o homem como centro do mundo. Tarefa por demais

23 Idem., op. cit., p.78.

${ }^{24}$ TOBEÑAS, José Castan. Humanismo y derecho. Madri: Ed.Instituto Editorial Reus, 1962 , p. 20

${ }^{25}$ OLIVEIRA, op. cit., p. 40.

26 NOGARE,Pedro Dalle. Humanismos e anti-humanismos: introdução à antropologia filosófica. 13 a ed. Petropólis: Vozes, 1994, p. 44.

27 TOBEÑAS op.cit., p. 130.

Resenha Eleitoral (Florianópolis), v. 20, n. 1, p. 201-220, jul. 2016 
difícil, uma vez que existem várias significações e diversas espécies de humanismos, como enfatiza Wolkmer (2003) ${ }^{28}$ sobre a pluralidade de humanismos existentes: greco-romano, renascentista, burguês individualista, cristão, existencialista, marxista e tantos outros.

Depreende-se, do até aqui colocado, que o humanismo é essencialmente o valor e a dignidade do homem, sendo considerado uma filosofia, uma doutrina ou até mesmo um projeto.

Suas características são arroladas por Caporale (2000) ${ }^{29}$ como: “a) eleger o ser humano como valor central; b) afirmar a igualdade de todos os seres humanos; c) reconhecer e considerar a diversidade (pessoal e cultural); d) valorizar a liberdade de idéias e crenças; e) desenvolver uma consciência que transcende a verdade absoluta, e f) repudiar toda e qualquer violência.".

O humanismo formal, metafísico que, como se sabe, tem sua gênese do humanismo moderno, há de ser redimensionado no contexto histórico social, dando efetividade prática em favor da dignidade humana. O humanismo que se pretende tratar, neste trabalho, refere-se ao humanismo concreto e pós-metafísico. Um humanismo que seja prático e que de fato atinja o vivenciar das pessoas como cidadãos, e não apenas formal, sendo desta forma distante e inatingível pelas pessoas que fazem parte da sociedade atual. Esse é nosso entendimento de um humanismo para o século XXI.

Para Paviani (2000) 30 "o conceito de humanismo pressupõe uma concepção do humano como centro da vida, das relações de produção e de comunicação, das relações entre os indivíduos e as sociedades.". Por outro lado, "não se trata apenas do humano como valor, mas do humano como realidade ético-ontológica. O humano não é um adjetivo, uma qualidade, mas o modo fundamental de existir no mundo." ${ }^{31}$.

${ }^{28}$ WOLKMER, Antonio Carlos. Humanismo e cultura jurídica latino-americana. Humanismo e cultura Jurídica no Brasil. Florianópolis: Fundação Boiteux, 2003, p.21.

${ }^{29}$ CAPORALE, Rocco. Algumas reflexões críticas sobre o conceito de humanismo. In: PAVIANI, J. e DAL RI JR.,A. Globalização e humanismo latino. Porto Alegre:Edipuc Cassamarca, 2000., p. 20.

30 PAVIANI, Jayme. O humanismo latino no processo de globalização. In: PAVIANI, Jayme e DAL RI JR, Arno (Orgs.) Globalização e humanismo latino. Porto Alegre: EDIPUCRS, 2000, p.26-27.

${ }^{31}$ Idem, p. 27. 
Na mesma perspectiva, mas já no âmbito do direito, outros autores ${ }^{32}$ se propuseram a interpelar o direito a partir do humanismo. Procurar operacionalizar uma prática e uma elaboração teórica estimuladora da ruptura com a tradição legalista é um desafio para o humanismo que se almeja (concreto, prático, real). Entende-se possível, a partir dessa prática, pautar a educação jurídica por uma visão humanista, vinculada na transformação social, de modo a atender às necessidades humanas fundamentais.

O ensino superior de modo geral, e a educação jurídica em particular, podem ser elos entre a educação e a cidadania. Esta é uma das formas essenciais para que a dignidade da pessoa humana não seja apenas promessa constitucional, mas realidade. Como salientou De Polli (2000) ${ }^{33}$, neste contexto, também urge "pensar numa universidade que retorne a falar à sociedade, que não seja somente um espaço de erudição ou de produção de diplomas e títulos formais para inserção na vida social.”.

A matriz da formação dos operadores jurídicos, ou seja, aqueles que irão ensinar e operar o direito, está, por óbvio, na universidade, a qual deveria atuar como previsto na Declaração Mundial sobre Educação Superior no século XXI:

a) preservar e desenvolver suas funções fundamentais, submetendo todas as suas atividades às exigências da ética e do rigor científico e intelectual;

b) poder opinar em problemas éticos, culturais e sociais de forma completamente independente e com consciência plena de suas responsabilidades, por exercerem um tipo de autoridade intelectual que a sociedade necessita, para assim ajudá-la a refletir, compreender e agir;

c) ampliar suas funções críticas e prospectivas mediante uma análise permanente das novas tendências sociais, econômicas, cultu-

32 DAL RI JUNIOR, Arno. O humanismo jurídico segundo Friederich Karl Von Savigny. PAVIANI, Jayme. DAL RI JUNIOR. Arno (Orgs.). Humanismo latino no Brasil hoje. Belo Horizonte: PUCMinas, 2001. p. 150-167; WOLKMER, Antonio Carlos. Humanismo e cultura jurídica latino-americana. WOLKMER, Antonio Carlos (org.). Humanismo e cultura jurídica no Brasil. Florianópolis: Boiteux, 2003. p. 19-40; DE LA TORRE RANGEL. Jesus Antonio. Jusnaturalismo histórico analógico. Espanha (no prelo).

33 DE POLI, Dino. Prefácio. In: PAVIANI ,J. e DAL RI R.,A. (Orgs.). Globalização e humanismo latino. Porto Alegre: EDIPUCRS/Cassamarca, 2000, p.13.

Resenha Eleitoral (Florianópolis), v. 20, n. 1, p. 201-220, jul. 2016 
rais e políticas, atuando assim como uma referência para a previsão, alerta e prevenção;

d) utilizar sua capacidade intelectual e prestígio moral para defender e difundir ativamente os valores aceitos universalmente, particularmente a paz, a justiça, a liberdade igualdade e solidariedade[...];

e) desfrutar de liberdade acadêmica e autonomia plenas, vistas como um conjunto de direitos e obrigações, sendo simultaneamente responsáveis com a sociedade e prestando contas à mesma; f) desempenhar seu papel na identificação e tratamento dos problemas que afetam o bem-estar das comunidades, nações e sociedade global. ${ }^{34}$ (UNESCO, 1999, p. 33).

Sendo assim, as instituções de educação jurídica de modo geral, e os cursos de direito em particular, precisam reconhecer que atuam na e com a sociedade. Ou melhor, são instituições sociais, com ações e práticas sociais. Para Chauí (2003) ${ }^{35}$, “a universidade é uma instituição social e como tal exprime, de maneira determinada, a estrutura e o modo de funcionamento da sociedade.".

Diante dessa afirmação, é importante lembrar o que Dias ${ }^{36}$ assevera

a educação superior deve se esforçar para adaptar-se permanentemente às mudanças da sociedade que está continuamente em transição. Mudanças permanentes, significam crises permanentes[...]. A verdade é que na vida das sociedades a instabilidade é a regra, a estabilidade é a exceção. (DIAS, 1999, p. 62).

Os cursos de direito, dado à complexidade do mundo atual, por fazerem parte do universo da educação superior, precisam perceber que podem, através da sua competência técnica, propor a solução para os

${ }_{34}$ UNESCO. Tendências da Educação Superior para o Século XXI. Brasília: UNESCO/CRUB, 1999, p.33.

${ }^{35}$ CHAUÍ, Marilena. Universidade: Organização ou instituição social. UNESCO: $A$ Universidade na encruzilhada - seminário universidade: por que e como reformar. Brasília: UNESCO/SESU/MEC, 2003, p. 67.

${ }^{36}$ DIAS, Marco Antônio Rodrigues. Políticas para o Ensino Superior a partir da Conferência de Paris. In: Universidade e Sociedade. Ano IX, n. 18, março de 1999, p. 62. 
problemas dentro de enfoque interdisciplinar. Para tanto, acompanhando a ideia de Morin (2000) ${ }^{37}$ é imprescindível

promover grande remembramento dos conhecimentos oriundos das ciências naturais, a fim de situar a condição humana no mundo, dos conhecimentos derivados das ciências humanas para colocar em evidência a multidimensionalidade e a complexidade humana, bem como integrar a contribuição inestimável das humanidades, não somente a filosofia e a história, mas também a literatura, a poesia[...]. (MORIN, 2000, p. 48).

Por outro lado, cabe à educação do futuro cuidar para que a ideia de unidade da espécie humana não apague a idéia de diversidade, e que a diversidade não apague a da unidade.

O ensino do direito deve pautar-se na compreensão entre as pessoas como condição e garantia da solidariedade intelectual e moral da humanidade, e para compreender, além de comunicar e explicar, é preciso pautar-se na ética da alteridade. Para isso, a empatia deve ser trabalhada, "a compreensão pede abertura, simpatia e generosidade. Essa é a ética da compreensão que tem por conceito, a arte de viver que nos demanda em primeiro lugar, compreender de modo desinteressado [...] compreender a incompreensão." ${ }^{38}$.

Dentro dessa perspectiva antropoética, e entendendo que indivíduo e sociedade coexistem, a democracia deve ser ensinada por ser o instrumento produtor e produto dos cidadãos no momento de sua interatividade.

Com esse novo olhar, a Resolução n o 09/2004 do Conselho Nacional de Educação, a qual fixa as diretrizes curriculares para o curso de Direito, precisa ser (re)interpretada. Urge que o aprendizado técnico mencionado na referida resolução se volte para o compromisso que a universidade pode assumir com a sociedade, com a dignidade do ser humano no contexto onde está inserida, preocupando-se para que o futuro profissional esteja engajado e possa responder às expectativas da sociedade.

37 MORIN, Edgar. Os sete saberes necessários à educação do futuro. Tradução de Catarina Eleonora F. da Silva e Jeanne Sawaya. São Paulo: Cortez, 2000, p. 48.

38 Idem, ibidem, p. 95.

Resenha Eleitoral (Florianópolis), v. 20, n. 1, p. 201-220, jul. 2016 
Fagundes ${ }^{39}$ enfatiza que

Fica difícil entender a existência de uma Universidade desprovida de qualquer compromisso social. Qual a razão ou o suporte de Universidade que não serve ou não interessa a ninguém? A afirmação de que a Universidade é descompromissada e desinteressada contribui exatamente, para ocultar os reais compromissos e interesses a que ela serve. (FAGUNDES, 1983, p. 160).

O curso de Direito pode intervir na vida das pessoas, através de suas várias vertentes, individual e coletivamente, tornando o acesso à justiça efetivo e qualitativo, transformando, assim, a sociedade na qual está inserido. Para tanto, o Direito necessita estar voltado para uma visão ética humanista, sendo canal de transformação social com vistas à dignidade da pessoa humana.

Com propriedade enfatiza Wolkmer ${ }^{40}$

Ganha sentido, assim, articular e operacionalizar um projeto de cunho humanista no Direito, ainda que se reconheçam as dificuldades de sua elaboração teórica e efetividade prática. Certamente que uma filosofia jurídica humanista, estimuladora da ruptura com a tradição legalista idealizadora e com o viés tecno-formalista (fundados em falsos humanismos) não deve assumir um traço destrutivo, mas se impõe e adquire legitimidade, numa sociedade de exclusão, injustiças e desigualdade. (WOLKER, 2003, p. 4).

A promoção da justiça social, amplamente discutida pelos constituintes de 1988, ainda é promessa. As desigualdades individuais, regionais e globais, somadas à exclusão e à injustiça social, são gritantes. O reconhecimento do indivíduo, enquanto cidadão, ainda não se concretizou. A dignidade do ser humano, em pleno século XXI, ainda está atrofiada. É necessária uma ação prática da política que não objetive somente o desenvolvimento econômico, mas a busca incessante da felicidade do ser humano.

39 FAGUNDES, J. Universidade e compromisso social. Campinas: Unicamp, 1983, p. 160 .

40 WOLKMER, Antônio Carlos. (org.). Humanismo e cultura jurídica no Brasil. Florianópolis: Fundação Boiteux, 2003, p. 4. 
Neste contexto, urge repensar e redimensionar o ensino do direito, com alicerces humanistas. Discutir o humanismo como uma forma de mudar o ensino. Uma das maneiras mais visíveis seria inserir disciplinas que promovam os valores humanos na estrutura curricular do curso de Direito; e também, reformulando métodos de ensino aprendizagem, capacitando efetivamente os docentes de forma que o comprometimento entre discentes, docentes e coordenação do curso caminhem juntos, e neste caminhar olhem para a mesma direção. Este é o desafio.

Assim, no magistério de Wolkmer ${ }^{41}$

Faz-se necessário, portanto, transpor a filosofia jurídica embasada em um humanismo atrofiado e resgatar os valores do humanismo autêntico, calcado na ética e na alteridade, para servir de fundamentos a nova justiça ao novo Direito. É nessa perspectiva que podemos incorporar as reflexões humanistas, agora, numa perspectiva latino-américa, que nos remeta para a busca de uma noção compartilhada e geral da natureza humana, sem entendê-la de uma forma essencialmente a-histórica, mas como potencializadora de uma nova configuração social. (WOLKER, 2003, p. 4).

Diante desta nova perspectiva humanista, entende-se possível aplicá-la à educação jurídica com vistas ao acesso à justiça, proporcionado pelo curso de Direito, enfatizando seu papel transformador.

\section{Considerações Finais}

A importância de se estudar o educação jurídica e a aplicação da teoria do humanismo no seu contexto, a fim de verificar uma possibilidade para construção e efetivação da cidadania, reside na necessidade de se formar operadores de direito conhecedores e comprometidos com a sociedade na qual estão inseridos.

Muitos estudos sobre a educação jurídica já foram produzidos, porém, importante ressaltar, que se faz necessário um estudo apurado sobre suas características e sobre os resultados a que se propõem, bem como se tais cursos, ao adotarem o humanismo como essência de sua estrutura, podem atender às demandas sociais nas quais estão inseridos.

${ }^{41}$ WOLKMER, 2003, p.04.

Resenha Eleitoral (Florianópolis), v. 20, n. 1, p. 201-220, jul. 2016 
Considerando que o discente do curso de direito tem capacidade de construir posturas, deixando de ser apenas mero espectador das transformações sociais, ele deve estar consciente e ser capaz de assumir novas posições, conhecendo seu papel e lutando pelo exercício da cidadania. Deve-se buscar instigar nesse ator social uma atividade positiva para integrar-se no objetivo de construir uma realidade mais justa, minimizando a exclusão hoje existente. Este processo passa necessariamente pela figura do docente do ensino superior, que não pode ficar atrelado à técnica profissional, mas entender e colocar em prática a sua função educativa.

Finalizando, o humanismo inserido efetivamente no ensino do direito, pode ser uma opção viável e concreta. Humanizando o futuro profissonal do Direito pode-se fortalecer e fazer crescer uma corrente de sensibilidade e solidariedade no seio dos atores da sociedade, e, consequentemente, na estrutura jurisdicional do Estado.

Essa prática humanista identificará caminhos que criarão elos entre a educação, cidadania e dignidade humana. Esse caminhar da prática humanista levará à transformação da sociedade pelo viés da educação.

\section{Referências}

ANDRADE, Vera Regina P. de. Cidadania: do direito aos direitos humanos. São Paulo: Acadêmica, 1993.

BRASIL. Constituição da República Federativa do Brasil. São Paulo: Saraiva, 2004.

CAPPELLETTI, Mauro, GARTH, Bryant. Acesso à justiça. Tradução de Ellen Gracie Nothfleet. Porto Alegre. Antonio Fabris Editor, 1988.

CAPORALE, Rocco. “Algumas Reflexões Críticas sobre o Conceito de Humanismo”. In: PAVIANI, J e DAL RI JR., A. (Orgs.). Globalização e humanismo latino. Porto Alegre:EDIPUCRS/Casamarca, 2000.

CARNEIRO, Paulo Cezar Pinheiro. Acesso à justiça. Rio de Janeiro: Forense, 1999.

CHAUÍ, Marilena. Universidade: Organização ou instituição social. UNESCO: A Universidade na encruzilhada - seminário universidade: por que e como reformar. Brasília: UNESCO/SESU/MEC, 2003.

DE LA TORRE RANGEL. Jesus Antonio. Jusnaturalismo histórico analógico. Espanha (no prelo). 
DELGADO, Daniel Garcia. Estado nación y globalización. Buenos Aires: Aruel, 1998.

DE POLI, Dino. Prefácio. In: PAVIANI, J e DAL RI JR.,A. (Orgs.). Globalização e humanismo latino. Porto Alegre: EDIPUCRS/Casamarca, 2000.

DIAS, Marco Antônio Rodrigues. Políticas para o Ensino Superior a partir da Conferência de Paris. In: Universidade e Sociedade. Ano IX, n. 18. março de 1999.

FAGUNDES, J. Universidade e compromisso social. Campinas: Unicamp, 1983.

HELD, David, MACGREW, Anthony. Prós e contras da globalização. Tradução de Vera Ribeiro. Rio de Janeiro: Jorge Zahar, 2001.

MARSHALL, T. H. Cidadania, classe social e status. Tradução Meton Porto Gadelha. Rio de Janeiro: Forense, 1977.

MINISTÉRIO DA EDUCAÇÃO (MEC). Portaria 1886/94. Fixa diretrizes para os cursos de direito. Disponível em: $<$ http://www.mec.gov.br $>$ Acesso em: 25 maio 2004.

MORIN, Edgar. Os sete saberes necessários à educação do futuro. Tradução de Catarina Eleonora F. da Silva e Jeanne Sawaya. São Paulo: Cortez, 2000 .

NOGARE, Pedro Dalle. Humanismos e anti-humanismos: introdução à antropologia filosófica. 13ª ed. Petropólis: Vozes, 1994.

OLIVEIRA, Odete Maria. Conceito de homem: mais humanista, mais transpessoal. Ijuí: Unijuí, 2006.

PAVIANI, Jaime; DAL RI JUNIOR, Arno (orgs.). Globalização e Humanismo Latino. Porto Alegre: EDIPUCRS, 2000.

Minas, 2001.

. Humanismo Latino no Brasil hoje. Belo Horizonte: PUC-

PEET, Richard. Mapas do mundo no fim da história. In SANTOS, Milton e outros (orgs.) Fim de século e globalização. São Paulo: Hucitec, 1994.

RODRIGUES, Horácio Wanderlei. Acesso à justiça no direito processual brasileiro. São Paulo: Acadêmica, 1994. 
SANCHES, Sydney. Acesso à justiça. Revista dos Tribunais, São Paulo, v. 621, jul. 1987.

SANTOS, Boaventura de Souza. A crítica da razão indolente: contra o desperdício da experiência - para um novo senso comun: a ciência, o direito e a política na transição paradigmática. São Paulo: Cortez, 2000.

pós-modernidade. São Paulo: Cortez, 1996.

. Pela mão de Alice: o social e o político na

TOBEÑAS, José Castan. Humanismo y derecho. Madri: Ed. Instituto Editorial Reus, 1962.

UNESCO. Tendências da Educação Superior para o Século XXI. Brasília: UNESCO/CRUB, 1999.

VILELA, Orlando. Iniciação filosófica. 2 ed. São Paulo: Dominus Editora, 1965.

WATANABE, Kazuo. Acesso à justiça e sociedade moderna. GRINOVER, Ada Pellegrini, DINAMARCO, Cândido Rangel, WATANABE, Kazuo (coords.). Participação e Processo. São Paulo: Revista dos Tribunais, 1988. . Assistência judiciária e o juizado especial de pequenas causas. Revista dos Tribunais. São Paulo, v. 617, mar. 1987.

WOLKMER, Antônio Carlos. (org.). Humanismo e cultura jurídica no Brasil. Florianópolis: Fundação Boiteux, 2003.

Sirlane Melo - Advogada. Especialista em Direito. Mestre e Doutora em Direito pelo Curso de Pós-Graduação em Direito da Universidade Federal de Santa Catarina (CPGD/ UFSC). Professora Titular da disciplina de Estágio (Escritório Modelo de Assistência Jurídica - EMAJ) do Curso de Direito da Universidade do Planalto Catarinense - Uniplac. 